\title{
Limites na prática da missão religiosa: Charles Vincart, um caso emblemático
}

Franscino Oliveira Silva

\section{Introdução}

A Igreja particular da Arquidiocese de Montes Claros, às vésperas da comemoração de seu centenário como diocese (1910-2010), nos convida à pesquisa e divulgação de sua história que se dá no sertão norte-mineiro ${ }^{1}$. Quando seu primeiro bispo Dom João Antônio Pimenta (1911-1943) chegou a Montes Claros em 1911, os religiosos da Ordem Premonstratense já estavam na cidade desde 1903 e as Irmãs do Sagrado Coração de Maria de Berlaar, desde 1907. Os religiosos premonstratenses da Bélgica dirigiam a única paróquia na sede da nova diocese e o clero diocesano se encontrava nas outras paróquias da diocese. Na sua chegada, o bispo logo percebeu que a organização da missão premonstratense não andava bem, havia 4 padres premonstratenses na diocese de Montes Claros e outros premonstratenses se encontravam na diocese de Mariana: Cônego Alderico Paw, o prior e cônegos Fesingher e Boalaerts. Dom João sugeriu ao Abade que os premonstratenses se reunissem numa só casa em Montes Claros, mas percebeu que o cônego Carlos Vincart impedia que a reunião dos padres num convento se tornasse realidade ${ }^{2}$. O próprio cônego considerava essa sugestão do bispo diocesano uma utopia.

\footnotetext{
${ }^{1}$ Este texto constitui, em certa medida, numa derivação de um capítulo de nosso livro Sub Umbra alarum tuarum: História da criação e organização da Diocese de Montes Claros (1903-1943). Belo Horizonte: Fumarc, 2005.

2 Carta de Dom João Antônio Pimenta ao Núncio Apostólico Dom Giuseppe Aversa aos 11 de novembro de 1915, in ASV, Nunziatura Apostolica in Brasil (1912-1916),
} 
Cônego Carlos Antônio Vincart é lembrado na história montes-clarense como alguém que iniciou um tempo novo em Montes Claros, onde existia apenas a paróquia de Nossa Senhora da Conceição e São José. Na verdade, ele trouxe novas experiências para trabalhar com o povo num esforço de inculturação na realidade do sertão de Minas. Da cidade de Huy, Bélgica, ele foi para a Abadia do Parc, a 25 de maio de 1891. Viajou para o Brasil em 1898. Chegou ao Brasil com apenas 25 anos de idade. Inicialmente foi para Congonhas do Campo, depois ele foi para Sete Lagoas para dirigir o Colégio Sagrado Coração de Jesus. Nomeado Vigário de Montes Claros, ali chegou a 27 de julho de 1903, em companhia do cônego Francisco Moureau (padre Chico). Organizou e administrou em Montes Claros um observatório Meteorológico, que funcionou por mais de 10 anos; também organizou um pequeno Museu de História Natural; fundou o Grêmio Literário Mont'Alverne; um Clube de amadores teatrais, que tomou o nome de São Genesco; uma biblioteca, o Colégio São Norberto, para meninos. No ano de 1904, ele preparou a recepção de Dom Joaquim Silvério de Souza, então bispo coadjutor de Diamantina, em Montes Claros. Fundou o semanário religioso $A$ Verdade, que deu seu primeiro número a $1^{\circ}$. de maio de $1907^{3}$.

\section{Um caso emblemático: Cônego Vincart}

Após a posse do primeiro bispo na diocese de Montes Claros, o cônego Carlos Vincart foi nomeado Pró-Vigário Geral do Bispado no dia 15 de agosto de 1912. A Igreja Nossa Senhora da Conceição e São José passou a funcionar como Catedral da Diocese. Ele não estava mais sozinho na sua missão em Montes Claros. De certo modo como pároco de Montes Claros, longe da Abadia do Parc, estava na sede de um município que possuía um território maior

fasc. 771, 102 (Premostratensi): «A desorganização em que se acha a Missão premonstratense nesta diocese é devida ao Sr. Cônego Carlos Vincart. É tal o espírito deste sacerdote que nenhum dos seus confrades se resigna a viver junto d'elle; sendo esta a causa de que não possa ter Coadjutor, ficando a freguesia de Montes Claros, sede da diocese, muito mal servida».

${ }^{3} \mathrm{O}$ escritor Nelson Vianna atribui ao Jornal $A$ Verdade uma influência decisiva na criação da Diocese de Montes Claros, e ainda várias outras iniciativas que teriam beneficiado não só ao município de Montes Claros, como as demais comunidades norte-mineiras. O escritor parece desconhecer os motivos que levaram o cônego Carlos a deixar a cidade na manhã de 19 de julho de 1917, e partir para o Estado de São Paulo, onde foi integrar, na cidade de Jaú, o corpo de professores do Ateneu Jauense (Cf. N. VianNA, Efemérides Montesclarenses, 610). 
do que aquele da Bélgica. Com a chegada do bispo, ele começou a contar com a presença de alguém que lhe era superior.

Quando Dom João teve que apresentar as faltas cometidas pelo cônego Carlos, ele atribuiu a sua escolha como Pró-Vigário Geral, cargo da mais alta confiança e responsabilidade, à triste situação em que se encontrava a diocese por falta de clero. Ele esclareceu ao Núncio: «É o único padre que até agora existia na séde da diocese» ${ }^{4}$.

Cônego Vincart manteve uma constante correspondência com o Núncio Apostólico Dom Giuseppe Aversa (1912-1916) e com o superior da Ordem Premonstratense da Abadia do Parc. O fato de ser religioso, os aparentes bons serviços que realizava em Montes Claros e sua estreita amizade com os representantes de Roma no Brasil poderiam ter-lhe favorecido uma nomeação para primeiro bispo de Montes Claros. Após a chegada do bispo a Montes Claros, o cônego Carlos continua sendo uma referência para a Nunciatura Apostólica. No dia 23 de junho de 1913, o núncio Dom Giuseppe Aversa enviou uma carta ao cônego Carlos para obter uma informação a respeito de Dom João. O núncio acusava o recebimento de um telegrama enviado pelo padre Carlos Passos, vigário de Brasília de Minas, cujo conteúdo era:

Data venia venho chamar atenção de V. E. para os desmandos do desequilibrado Bispo de Montes Claros infrator escandaloso leis canônicas.

Clero geralmente descontente com esse bispo totalmente autoritário ${ }^{6}$.

O núncio deixava claro que reprovava uma linguagem assim tão pouco respeitosa em relação à autoridade suprema da Diocese e queria saber confidencialmente e, sob segredo, quem era este padre Carlos Passos e se verdadeiramente e por quais razões o clero estava descontente com o bispo de Montes Claros ${ }^{7}$.

4 Carta de Dom João Antônio Pimenta ao Núncio Apostólico Dom Giuseppe Aversa aos 11 de novembro de 1915, in ASV, Nunziatura Apostolica in Brasil (1912-1916), fasc. 771, 102v (Premostratensi). O grifo é nosso.

5 Giuseppe Aversa nasceu em Nápolis aos 21 de junho de 1862 e morreu em Mônaco (Baviera) aos 13 de abril de 1917. Núncio Apostólico no Brasil no período de 19121916. Foi nomeado Núncio Apostólico de Baviera aos 04 de dezembro de 1916 (Cf. G. DE MARCHI, Le Nunziature Apostoliche dal 1800 al 1956, 80).

6 Carta do Núncio Apostólico Dom Giuseppe Aversa ao Cônego Carlos Antônio Vincart aos 23 de junho de 1913, in ASV, Nunziatura Apostolica in Brasil (19121916), fasc. 771, 75 (Premostratensi).

7 Ibid. 
A resposta de cônego Carlos foi enviada numa carta do dia 4 de julho e recebida pelo núncio no dia 14 de julho de 1913, em Petrópolis. Ele afirmou que o padre Carlos Passos «é um padre às vezes inteligente e infelizmente desequilibrado». Naquela ocasião o bispo lhe havia retirado a provisão de vigário da paróquia Coração de Jesus porque ele exasperava o povo. Apesar da proibição formal do bispo, padre Carlos Passos continuou administrando os sacramentos do Matrimônio e do Batismo, escrevendo cartas injuriosas ao bispo. O cônego Carlos se explicou ao núncio, dizendo que não era seu hábito julgar seus superiores nem se queixar da conduta deles, ao oferecer as informações a respeito do bispo diocesano, atendia a um interesse do mesmo núncio. Segundo o cônego Carlos, o clero estava realmente descontente com Dom João, pois ele «é naturalmente muito vivo, às vezes vivo demais e não mede o alcance de suas palavras» e repreendia com violência os padres e, muitas vezes, sem razão. E acrescentou que naquela época dois padres deixaram a diocese, porque foram tratados violentamente pelo bispo diante dos empregados e de outras pessoas. O bispo dizia as acusações que tinha contra os padres a qualquer pessoa. Tudo isso favorecia o descontentamento do clero. E afirmou ainda:

enfim, aqui mesmo na cidade o amigo mais íntimo do bispo é precisamente o homem mais ativamente ímpio do lugar ${ }^{8}$.

Em 12 de março de 1916 o cônego Carlos declarou quem era este amigo de Dom João. Ao escrever ao Núncio disse que se tratava de Dr. Honorato José Alves, maçom professo e inimigo irreconciliável da Instituição católica ${ }^{9}$. Na mesma carta, o cônego Carlos afirmou que o adversário de Dr.

8 Carta de Cônego Carlos Vincart ao Núncio Apostólico D. Giuseppe Aversa aos 12 de março de 1916, in ASV, Nunziatura Apostolica in Brasi l (1912-1916), fasc. 771, 113v (Premostratensi): «Enfin ici em ville même l'ami le plus intime de Sa Grandeur est précisement l'homme le plus activement impie de l'endroit».

9 Ainda que a proibição dos pontífices seja bem clara sobre a participação dos católicos em sociedades secretas, a maçonaria do Brasil tinha suas diferenças da maçonaria da Europa, melhor conhecida pelo belga cônego Carlos Vincart. Ainda na década de 70, Hoornaert enaltece o papel da maçonaria na história do Brasil: «A maçonaria brasileira não tinha sido um movimento sem valor na evolução cultural, política e social do país. O seu grande mérito consistiu na formação de uma nova mentalidade, mais aberta, ativa e liberal, entre as elites da jovem nação. Ela havia concorrido para a preparação da independência de 1822 e concorreria mais tarde poderosamente na luta pela abolição em 1888. Ela reunia em seu seio homens de grande valor: basta enunciar aqui a figura de Luís Gama, filho de fidalgo e mãe preta, que escolheu a maçonaria para defender as suas idéias de igualdade entre as 
Honorato era Camillo Prates, homem de caráter limpo. É necessário observar que o cônego Carlos e o Deputado Camillo Prates sempre foram amigos. Em 1911, o jornal $A$ Verdade apresenta na sua primeira página o cônego Carlos como diretor do jornal e o Deputado Camillo Prates como redator. Ao oferecer tais informações a respeito de D. João e o outro político Dr. Honorato, cônego Carlos Vincart manifestava o desejo de ser útil ao núncio e permitir que ele pudesse mais tarde julgar melhor alguns acontecimentos possíveis.

Em 1915, porque agravava-se a situação da missão premonstratense e porque não tinha recebido resposta da que havia comunicado ao abade do Parc, Dom João pediu ao Núncio que resolvesse o problema, uma vez que a missão premonstratense estava cada vez mais decadente, e nessa mesma carta denunciou a atitude de cônego Carlos, pois, ele celebrava e administrava os sacramentos numa demonstração de falta de fé: «Faz tudo com precipitação escandalosa, sem atenção às rubricas e sem o respeito devido às cousas santas $\rangle^{10}$. Todos se queixavam do descaso com que celebrava a Confissão e o Matrimônio. Nos casamentos, contentava-se em receber o consentimento dos nubentes, sem atenção à práxis seguida no Brasil e prescrita pela Pastoral Coletiva.

No templo da Catedral tudo estava em desordem: assoalho cheio de buracos; o teto a gotejar por todas as partes; paredes com o reboco estragado; as toalhas dos altares, corporais quase sempre imundos. Tudo se apresentava como sinal de lástima e escândalo. $\mathrm{O}$ cônego Carlos freqüentava cinemas e outros ambientes proibidos expressamente pela Pastoral Coletiva. Ele fundou um clube de diversões, de cujo programa fazia parte um baile mensal. A sede do clube era em frente à Residência Episcopal. Diante das admoestações do bispo, ele se desculpava, dizendo que ia ao cinema para fiscalizar as fitas do cinema e o que se passava nessas reuniões.

raças» (E. HOORNAERT, «O Centenário da Posse de Dom Vital», REB, 32 [1972] 366). Outras informações a respeito desse diálogo entre Igreja e Maçonaria cf. J. A. F. BENIMELLI - al., Maçonaria e Igreja Católica: ontem, hoje e amanhã, São Paulo 1983.

${ }^{10}$ Dom João Antônio Pimenta desde o início de seu episcopado se preocupou com a situação da missão premonstratense. Em contínua comunicação com o Abade do Parc, apresentou-lhe a real situação do cônego Carlos Vincart. O Abade manifestou-se indiferente. Por isso, o bispo se lamentou junto ao Núncio: «Faz-me embaraço também à liberdade de acção a fraqueza do Abbade, ou talvez o fundado receio que elle tem de introduzir novamente na Abbadia um elemento perturbador) (Carta de Dom João Antônio Pimenta ao Núncio Apostólico D. Giuseppe Aversa aos 11 de novembro de 1915, in ASV, Nunziatura Apostolica in Brasil [1912-1916], fasc. 771, 102v (Premostratensi). O grifo é nosso. 
O bispo diocesano apresentou brevemente a realidade dos outros padres premonstratenses. A falta de organização regular os prejudicava muito, não observavam o voto de pobreza, usavam com abuso suas rendas, não faziam retiro espiritual. O bispo reconhecia que os cônegos Maurício Gaspar e Clemente Laurens tinham procedimento exemplar e os outros procediam regularmente. Estes trabalhavam muito. Contra o cônego Bento Maussen havia suspeitas graves, mas pareciam infundadas. Em 1915, além dos religiosos Carlos Vincart, Maurício Gaspar, Clemente Laurens, padre Chico e Bento Maussen, que estavam na diocese, havia três no arcebispado de Mariana, que para D. João, estavam sujeitos aos mesmos perigos. O bispo escreveu ao abade, indicando-lhe que o meio de salvar a Missão seria a reunião de todos os padres em Montes Claros, fundando-se nesta cidade um convento para centro com as rendas das paróquias por eles regidas, porém o Prior deixou claro para o bispo que tal idéia seria irrealizável, enquanto o cônego Carlos continuasse a semear tanta discórdia. Diante de tal desafio, Dom João afirmou que, para sanar tais dificuldades, o abade do Parc se mostrava de uma fraqueza lamentável. E assim sugeriu ao Núncio:
uma carta de V. Excia. a Sua Eminência o Sr. Cardeal De Lai ou ao Prefeito da Congregação dos Religiosos resolverá todas as dificuldades. Peço a V. Excia. que se exija do Ab- bade o imediato recolhimento do Sr. Cônego Vincart à $\mathrm{Ab}$ - badia $^{11}$.

Naquele tempo, Dom João afirmou que, sentindo-se incapaz de dirigir a diocese como queria, estava passando a Jesus Sacramentado o báculo pastoral. O bispo confessou ao Núncio que dali em diante seria o vil instrumento de que Jesus teria de se servir para reger seu povo. Ele rogou a São José que, pela sua intercessão, lhe fosse concedida a graça da docilidade e fiel correspondência às inspirações de Jesus Sacramentado. Nesta ocasião, Dom João recebeu uma Circular que considerou como providencial, datada de 8 de novembro de 1915, enviada pelo Núncio. A Circular pedia informações sobre coisas relativas a Ordens e Congregações religiosas. Em razão disso, ele enviou uma nova carta ao Núncio no dia 19 de novembro. Praticamente, repetiu as mesmas informações da carta que lhe havia enviado no dia 11 do mesmo mês. Nesta nova carta, ele acusou o cônego de se envolver na política local, e o seu jornal $A$ Verdade, ainda que se intitulasse órgão religioso,

\footnotetext{
11 Carta de Dom João Antônio Pimenta ao Núncio Apostólico D. Giuseppe Aversa aos 11 de novembro de 1915, in ASV, Nunziatura Apostolica in Brasil (1912-1916), fasc. 771, 103v (Premostratensi).
} 
servia somente para divulgar a opinião de seu diretor ${ }^{12}$. Quando ele publicou, neste jornal, artigos escritos em defesa do patrimônio da Catedral, ele apresentou uma conta de trezentos e tantos mil réis ao bispo.

Como político militante, o cônego Carlos cometia imprudências e faltas graves. Além de se meter nas intrigas dos pleitos eleitorais, servia-se das visitas pastorais para pedir votos. Na sua campanha política, procurava de todos os modos envolver o bispo e isto incomodava muito o bispo que procurava manter-se na neutralidade imposta pela prudência e pelos deveres do seu cargo ${ }^{13}$. Contudo, Dom João se sentia impedido de agir com a precisa liberdade, uma vez que os políticos e pessoas apoiadas pelo cônego Carlos iriam se voltar contra a autoridade episcopal.

O bispo também sabia do bom relacionamento existente entre o Núncio e cônego Carlos que tinha um parente pertencente ao corpo consular da Bélgica. Quando esteve em Caracas - Venezuela, antes de vir para o Brasil, o Núncio D. Giuseppe Aversa conheceu o embaixador da Bélgica junto aquele governo o Sr. Leon Vincart. Ele era tio do cônego Carlos Vincart. O embaixador recomendou o seu sobrinho ao Núncio Apostólico. Quando chegou ao Brasil e ficou sabendo que o cônego Carlos era Pró-Vigário Geral da diocese, entendeu que o cônego era já merecedor da confiança do bispo de Montes Claros $^{14}$. Dom João acreditava que, depois de acompanhar bem o procedimento do cônego, o Núncio estaria mais atento à amizade muito interesseira do cônego. O Núncio tinha conhecimento de que mesmo o Santo Padre Pio $\mathrm{X}$ mantinha-se a par dos desafios que Dom João enfrentava para administrar bem a diocese e salvar a Missão dos premonstratenses.

12 Num artigo desse jornal, datado de 1911, aparece uma forte crítica ao presidente de Minas Gerais. Nessa época o presidente de Minas era Júlio Bueno Brandão (19101914), enquanto o presidente da câmara em Montes Claros era Dr. João José Alves (1909-1912 e 1917-1922): «Ora, o atual presidente de Minas é um coronel, um pobre tocador de clarineta a quem investiram da mais alta função administrativa [...]. Não se governa a um povo livre por linhas oblíquas, com subterfúgios e com manhas, senão as claras e pela linha reta do direito e da justiça. Não reconhecemos a legalidade das atuais câmaras municipais; cumprimos o nosso dever cívico: - cada um cumpra o seu» (A. A. TEIXEIRA, «Imposto Municipal», in A Verdade, 176 [8 abril 1911] 3, in Hemeroteca Pública do Estado de Minas Gerais). Nessa época, o diretor do jornal era o cônego Carlos Vincart e o redator era Deputado Camillo Prates.

13 Além disso, «no catolicismo romanizado perdurava uma visão sobrenaturalista da existência, com certa desvalorização da atuação política e social» (R. AzzI, A Sé Primacial de Salvador: A Igreja Católica na Bahia [1551-2001], II, 194).

${ }^{14}$ Cf. Carta de D. Giuseppe Aversa ao Cardeal Gasparri, Secretário de Estado, aos 27 de janeiro de 1916, in ASV, Nunziatura Apostolica in Brasil (1912-1916), fasc. 771, 117 (Premostratensi). 


\section{Diligência Episcopal}

Na visita ad lamina ${ }^{15}$, o representante de Dom João fez uma minuciosa exposição dos tristes fatos ocorridos em Montes Claros, manifestando seu desejo da concentração, nesta cidade, da missão Premonstratense. Não podendo fazer pessoalmente a visita ad limina, para ir prestar contas pessoalmente à Cúria Romana de sua administração eclesiástica, Dom João delegou como seu representante o padre capuchinho Bernardino d'Apremont, no ano de 1914. E no fim da audiência, quando o procurador de Dom João quis levar consigo o relatório que estava sobre a mesa, a fim de apresentá-lo à Sagrada Congregação, o Papa Pio X lhe disse: «Não; deixe-o ficar ahi. Quero apresentá-lo por mim mesmo ao Sr. Cardeal De Lai» ${ }^{16}$. O falecimento do Santo Padre aos 20 de agosto de 1914 e o início da primeira guerra mundial não permitiram que Dom João saísse da angustiante situação em que se encontrava a diocese de Montes Claros.

No dia 27 de Janeiro de 1916, o Núncio enviou ao Secretário de Estado, Cardeal Pietro Gasparri ${ }^{17}$, uma carta cujo conteúdo retratava o compor-

15 D. João, durante seu episcopado, não fez pessoalmente nenhuma visita ad Limina. Por ocasião de sua segunda visita, ele pediu ao papa que fosse dispensado. Na visita $a d$ Limina de 1914, ele enviou como seu representante o padre capuchinho Bernardino d'Apremont. Explicou sua impossibilidade de fazer a visita, porque lhe faltavam os meios primários: «Primo vescovo di una diocesi poverissima, creata senza patrimônio, ho impiegato tutte le parche rendite nella costruzione del palazzo episcopale e ultimamente nella costruzione del Seminario»». A seca na região de sua diocese, preços altos das passagens, em conseqüência da guerra, e sua idade de 60 anos são ainda motivos que lhe dificultam a realização da visita (Cf. Carta de D. João Antônio Pimenta ao Papa Bento XV aos 13 de dezembro de 1920, in ASV, S. Congregazione Concistoriale, Visitas Ad Limina, 528 Montisclaren: atos das Visitas ad Limina de 1914 e 1920 [folhas não numeradas]). Supõe-se que seja conhecida dos leitores essa instituição eclesiástica que consiste na visita periódica que os bispos fazem a Roma, em particular aos sepulcros (limina) dos Apóstolos Pedro e Paulo, aproveitando a ocasião para manifestar a comunhão com toda a Igreja Universal e informando ao Papa sobre o estado de suas respectivas dioceses (Cf. M. Milagros CÁRCEL ORTí - V. CÁrCEL ORTí, Historia, Derecho y Diplomática de la visita ad limina, València 1990).

${ }^{16}$ Carta de Dom João Antônio Pimenta ao Núncio Apostólico D. Giuseppe Aversa aos 19 de novembro de 1915, in ASV, Nunziatura Apostolica in Brasil (1912-1916), fasc. 771, 106 (Premostratensi). O grifo é nosso.

17 Cardeal Pietro Gasparri nasceu aos 5 de maio de 1852 em Ussita (Norcia) e faleceu aos 18 de novembro de 1934 em Roma. Foi nomeado Secretário de Estado aos 13 de outubro de 1914, e permaneceu neste cargo até 1930 (Cf. G. DE MARCHI, Le Nunziature Apostoliche dal 1800 al 1956, 14). 
tamento do cônego premonstratense Carlos Vincart, a situação da missão premonstratense no Norte de Minas e o atual estado da diocese. A resposta do Cardeal Gasparri, datada a 05 de março de 1916, comunicava ao Núncio que o Santo Padre Bento XV (1914-1922) ordenara ao Abade dos cônegos premonstratenses do Parc o retorno de cônego Carlos à Bélgica ${ }^{18}$, mas esta carta só chegou ao Núncio no dia $1^{\circ}$. de abril de 1916 e neste ínterim ele tinha recebido uma carta do cônego Carlos, afirmando que as relações entre o bispo e os religiosos e religiosas estavam tão tensas que, de um momento para outro, eles poderiam deixar em massa a Diocese de Montes Claros.

Segundo o cônego Carlos, as Irmãs do Sagrado Coração de Maria de Berlaar também estavam descontentes com a atuação do bispo. Nos trabalhos que faziam no Colégio e no Hospital experimentavam sempre a má vontade do bispo. As irmãs haviam comunicado ao Cardeal Mercier, arcebispo de Malinas ${ }^{19}$, que após a guerra elas iriam retornar à Bélgica ou mudar de diocese. Assegurou ao Núncio que tanto a Madre Superiora como o Car-

${ }^{18}$ Uma parte da carta resume bem as informações apresentadas pelo Núncio ao Cardeal Gasparri a respeito do Cônego Carlos: «La condotta di lui é molto leggiera. Sembra egli mancare di zelo e di spirito ecclesiastico. È questo il principale motivo del nessuno progresso spirituale in Montes Claros. Il Vincart, inoltre, è causa unica, perchè $i$ Canonici Premostratensi di Parc, che hanno una missione nel Nord di Minas, non si riuniscono in communità regolare e vivono sparpagliati, sono in una parrocchia, altri in altre, con danno evidente della santificazione propria e dei fedeli. I suoi confratelli non vogliono convivere con lui pel suo carattere difficile e irritabile. Tra altre cose egli si è immischiato molto nella politica locale. Ed è questa la ragione per cui il Vescovo non può sbarassarsi lui del Vincart, temendo che dopo gli accadrebbero grandi guai dai politicanti amici del suo Pro-Vicario Generale» (Carta do Núncio Dom Giuseppe Aversa ao Cardeal Gasparri aos 27 de Janeiro de 1916, in ASV, Nunziatura Apostolica in Brasil [1912-1916], fasc. 771, 118 [Premostratensi]). O grifo é nosso.

19 Désiré Mercier, filósofo, fundador do Instituto de Filosofia da Universidade de Louvain, cardeal e primaz da Bélgica. Ele nasceu aos 21 de novembro de $1851 \mathrm{em}$ Braine l'Alleud e morreu aos 23 de janeiro de 1926 em Malinas. Foi ordenado sacerdote em 1874 pelo Núncio Apostólico Dom Cattani. No ano de 1877, dois anos antes da encíclica Aeterni Patris, o ensinamento de Mercier já era na mesma linha da futura encíclica. Segundo Francesco Morandini, os biógrafos gostam de ressaltar que Mercier foi o homem capaz de compreender Leão XIII e que Leão XIII foi o papa capaz de compreender Mercier. Mercier foi criado Cardeal e Primaz da Bélgica por Pio X, tornando-se uma das mais eminentes figuras eclesiásticas da primeira metade do século XX. Durante a primeira guerra (1914-1918), ele trabalhou intensamente na defesa dos direitos de seu povo durante o tempo da ocupação alemã (Cf. F. MORANDINI, «Mercier, Désiré», in Enciclopedia Cattolica, VIII, Firenze 1950, 713-716). A tradução é nossa. 
deal Mercier exigiam de maneira absoluta a presença de premonstratenses belgas junto às fundações belgas destas religiosas no Brasil. O cônego Carlos ainda chamou de utopia o desejo do bispo de reunir todos os premonstratenses em Montes Claros: "Os cônegos que se encontram na diocese de Mariana não querem ouvir falar do Sertão». Os motivos de saúde eram a desculpa que encontravam ${ }^{20}$.

Nesta ocasião, o Núncio escreveu a Dom João, pedindo-lhe explicações, garantindo-lhe que o Santo Padre teria se mostrado benignamente propenso para acolher suas sugestões a respeito da retirada do cônego Carlos, mas se as afirmações do cônego Carlos fossem verdadeiras, ele não sabia como iria resolver o problema. Na busca de um juízo claro e seguro, o Núncio pediu ao bispo que lhe apresentasse o estado real dos fatos ${ }^{21}$.

O bispo de Montes Claros procurou imediatamente o meio necessário para apresentar ao Núncio a comprovação de suas afirmações, por isso enviou aos confrades do cônego Carlos o seguinte questionário:

$\mathbf{1}^{\boldsymbol{o}}$. Quais as dificuldades que lhe tenham sido criadas pela Autoridade Eclesiástica diocesana no exercício de seu ministério?

$2^{o}$. Se é verdade ou não que tenha recebido provas de alto apreço e particular consideração por parte desta Autoridade;

$3^{\boldsymbol{o}}$. Se têm sido ou não acolhidos com benevolência todos os pedidos e requisições de V. Revma., quer em seu benefício, quer pelo bem das almas;

$4^{o}$. Se é verdade que V. Revma. se julga na impossibilidade de exercer seu ministério nesta diocese; e no caso afirmativo, porque motivos ${ }^{22}$.

Padre Chico, de forma breve, respondeu ao bispo que não havia experimentado nenhuma dificuldade no exercício de seu ministério, sempre recebeu provas de estima e consideração, com nomeações para cargo de responsabilidade e confiança, foi sempre atendido prontamente pelo bispo nos pedidos que lhe fez a seu próprio favor e a bem das almas que lhe foram confiadas, assegurando-lhe que nunca passou pela sua mente retirar-se da diocese, salvo ordem superior ou motivo imperioso independente de sua vontade.

${ }^{20}$ Carta do Cônego Carlos Vincart ao Núncio D. Giuseppe Aversa aos 30 de março de 1916, in ASV, Nunziatura Apostolica in Brasil (1912-1916), fasc. 771, 111 (Premostratensi). O grifo é nosso.

21 Cf. Carta de Dom Giuseppe Aversa a Dom João Antônio Pimenta aos 07 de abril de 1916, in ASV, Nunziatura Apostolica in Brasil (1912-1916), fasc. 771, 123 (Premostratensi).

22 Esse questionário foi enviado no dia 19 de abril de 1916 aos cônegos: Francisco de Paula Moureau, Bento Uberto Maussen, Maurício Gaspar. A resposta foi imediata. Cf. Cartas dos padres premonstratenses, in ASV, Nunziatura Apostolica in Brasil (19121916), fasc. 771, 127-131-v (Premostratensi). 
O cônego Bento Humberto Maussen, desde que o bispo tomou posse da diocese, não experimentou qualquer dificuldade no exercício de seu ministério, sempre experimentou a estima e consideração do bispo, tanto nas paróquias que administrou como nas visitas pastorais em que o acompanhou mais de perto, quando pôde apreciar as virtudes do bispo e seu zelo apostólico para com os vigários em geral, em todo tempo foram atendidos, com especial benevolência, as solicitações feitas em seu benefício, em benefício dos colegas premonstratenses e dos seus paroquianos e afirmou que nunca lhe passou pela mente retirar-se da diocese. Ainda esclareceu algo ao bispo acerca do cônego Carlos, quando foi coadjutor dele em Montes Claros, durante 7 anos. Segundo cônego Bento, o cônego Carlos dificultava as aspirações nobres de seus colegas e o exercício pastoral na freguesia, criticava e abolia até o bem que se fazia. Cônego Carlos nunca fazia a pregação nas missas dominicais senão duas ou três vezes durante cinco anos, ridicularizando os confrades que se dedicavam a este ministério ou a qualquer outro bem espiritual da paróquia.

O cônego Maurício Gaspar disse que absolutamente nenhuma dificuldade foi criada pela autoridade eclesiástica diocesana no exercício de seu ministério, sentia-se feliz com o modo como era tratado pelo bispo e seus pedidos foram acolhidos sempre com benevolência pelo bispo. Ele nunca havia se queixado de ter sido impossibilitado no exercício de seu ministério. Ao contrário, tinha muitíssimas provas oficiais, faculdades especiais que the foram concedidas para facilitar o seu ministério.

No dia 14 de abril de 1916, o abade do Parc (Bélgica) Quirin G. Nols escreveu ao cônego Carlos para comunicar sua decisão:

Por causa de circunstâncias especiais e por motivos que explicarei mais tarde, eu decidi, depois de refletir, de chamá-lo definitivamente à Bélgica; portanto, queira considerar esta decisão como irrevogável ${ }^{23}$.

${ }^{23}$ Carta do Abade Quirin G. Nols ao Cônego Carlos Vincart aos 16 de abril de 1916, in ASV, Nunziatura Apostolica in Brasil (1912-1916), fasc. 771, 133 (Premostratensi): «À cause de circonstances spéciales et pour des motifs que je vous exposerai plus tard, $\mathrm{j}$ 'ai décidé, après avis, de vous rappeler définitivement em Belgique, veuillez donc considérer cette décision comme irrévocable». A tradução é nossa. 
Ele foi orientado para fazer as reparações necessárias, observando os votos de religião e as prescrições canônicas, tudo isto para o bem da diocese e da missão, oferecendo generosamente aquele sacrifício ao Sagrado Coração de Jesus ${ }^{24}$.

Ainda que a Secretaria de Estado do Vaticano e a Abadia do Parc houvessem confirmado o retorno do cônego Carlos à Bélgica, Dom João remeteu ao Vaticano a última resposta que recebeu do cônego Clemente Laurens $^{25}$, segundo o bispo, um sacerdote exemplar. Com uma resposta de 14 páginas do côn. Clemente, Dom João acreditava que ficaria assim provado até à evidência que o cônego Carlos Vincart não era digno da menor confiança, pois não trepidava diante da mentira e da calúnia para conseguir seus fins. Com relação às irmãs do Sagrado Coração de Maria, Dom João soube que elas se queixavam dele, atribuiu isto aos enredos do côn. Carlos, por isso procurou logo as irmãs para ouvi-las e, finalmente garantiu que estava bem com as irmãs.

Quando chegou a Montes Claros, no ano de 1912, cônego Clemente foi recebido durante três meses na residência episcopal. Ali foi tratado com generosidade pelo bispo. Naquela época ele era o padre mais novo do bispado. Desde esta estada na sede da diocese, ele sempre recebeu provas de particular consideração. Recebeu faculdades extraordinárias para auxiliar o cônego Carlos no serviço da Paróquia, foi convidado para ajudar nas cerimônias pontificais e foi nomeado Defensor Vinculi Matrimonialis ${ }^{26}$. O cône-

24 Ibid.

25 Nasceu em Lovaina, Bélgica, aos 15 de fevereiro de 1885. Aos 17 anos entrou para o Seminário de Malinas, onde cursou Filosofia e Teologia. Em 1906, ele entrou para a Ordem Premonstratense, Abadia do Parc, tendo sido ordenado diácono em Malinas e presbítero em Lovaina. Em 1911 foi enviado ao Brasil como missionário. Foi vigário cooperador de Bocaiúva durante 6 anos. Na arquidiocese de Mariana foi pároco de Catas Altas, depois capelão da Santa Casa de Ouro Preto. Voltou para a diocese Montes Claros a pedido do bispo e foi pároco de Jequitaí de 1920 até 1967, data de sua morte. Publicações: Este Boletim é para colocar num lugar visível na casa e fazer lêr pelos outros: muitas conversões se devem às boas leituras!, Juiz de Fora 1943; Lembranças dos meus trinta e cinco anos de Missão, Jequitaí 1946. Em 1954 ele obteve o decreto de secularização e foi incardinado nessa diocese (Cf. «Clemente Leopoldo Laurens - Necrologia», REB, 27 [1967] 509).

${ }^{26}$ A instituição do defensor do vínculo matrimonial ocorreu no século XVIIII, por obra do Papa Bento XIV, com a Constituição Apostólica Dei miseratione de 3 de novembro de 1741. Sua função era de tutelar a validade do vínculo matrimonial (precedentemente, essa tutela competia ao mesmo juiz), recebendo o nome inicialmente de defensor matrimonii. Poucos anos depois, com a constituição Nimiam licentiam do mesmo Pontífice (18 maio 1748), a sua competência se estendeu ao 
go observava que o Bispo sabia animar os seus padres que eram de boa vontade e estimulava as iniciativas por parte deles. A maior parte da resposta escrita pelo cônego Laurens foi dedicada a apresentar o modo como cônego Vincart procedia no exercício dos cargos que ocupava, e de modo particular como Pro-Vigário Geral ${ }^{27}$.

Segundo cônego Clemente, o cônego Vincart como Vigário de Montes Claros, deixava o povo 3 ou 4 domingos sem missa. Quando saía não avisava a ninguém a data de sua volta. Às vezes, os pobres iam até Montes Claros para o casamento, ficavam até 15 dias à espera do vigário, e como ele não chegava, eles iam casar-se perante o magistrado civil e não voltavam para o sacramento do Matrimônio. Quando estava na sede da paróquia, levava uma vida dissipada, assistia às representações do cinema e freqüentava os bailes. Celebrava as cerimônias ou atos litúrgicos: missas, confissões, batizados e casamentos, com celeridade e espantoso atropelamento. Ele não dava o bom exemplo a respeito das bebidas alcoólicas em casa e nos bares da cidade. Quanto ao horário para os atos litúrgicos, realizava-os «a qualquer hora» como dizia o povo. Naquela época, o último horário de missa era às 9 horas da manhã, mas aguardando o cônego Vincart muitas vezes, o povo devia permanecer até às 13 horas, para a celebração da missa. Não era zeloso com o templo e o decoro do culto divino. A conversação do cônego Carlos era pouco edificante, gostava de fazer gracejos e alusões ao casamento e às moças, falava mal da autoridade diocesana, dos colegas sacerdotes, sua casa era uma espécie de pensão, uma casa de confusão. Dois jovens sem religião habitaram na casa do cônego Carlos, não se confessavam, não iam à missa e isso escandalizava os paroquianos. Sem contar que o mesmo cônego não se confessava nem mesmo uma vez por ano, conforme testemunhavam os padres daquela época. Tendo a paróquia a extensão territorial como a superfície total da Bélgica, o cônego Carlos não aceitava coadjutores. Além disso, ele cometia inúmeras faltas na administração dos batismos e casamentos.

Como Diretor Espiritual das Irmãs, raramente ouvia as confissões e não se preocupava em realizar, de vez em quando, uma conferência espiritu-

vínculo da profissão religiosa, e no século XIX compreendeu também o vínculo da ordem subdiaconal (Instrução da Congregação do Concílio, 7 maio 1738). O Código de Direito Canônico de 1917 tornou obrigatório pelo direito comum a instituição do promotor de justiça e do defensor do vínculo em cada diocese (can. 1586) (Cf. L. ChiappetTA, Il Codice di Diritto Canonico - commento giuridico - pastorale, III, Roma 1986, 35-36).

27 Cf. Carta do Cônego Clemente Laurens ao Dom João Antônio Pimenta aos 21 de maio de 1916, in ASV, Nunziatura Apostolica in Brasil (1912-1916), fasc. 771, 138148 (Premostratensi). 
al sempre necessária às religiosas. Na saudação que fez às irmãs, quando chegaram da Bélgica, ele disse: «Eu não posso alimentar tantas pessoas!». E assim, ele nunca se mostrou animado e dedicado para ajudar as religiosas na fundação do Colégio. Como Reitor da residência dos padres, ele nunca favoreceu o espírito de iniciativa dos coadjutores para fundar em Montes Claros, uma casa central da ordem, permitindo que o bispo encontrasse a missão organizada.

Como Pro-Vigário Geral, apresentava negligência no expediente. Fazia as dispensas com pouca atenção, ora sem assinatura, ora sem o carimbo da cúria. $\mathrm{Na}$ ausência do bispo, admitia à diocese e confiava uma paróquia a algum sacerdote cujos papéis não inspiravam confiança e não observava o segredo nos negócios. Para secretário do expediente, ele escolheu um rapaz desvirtuoso e impiedoso que mais tarde, se tornou culpável de um assassinato. O criminoso fugiu para Goiás, depois voltou a Montes Claros ${ }^{28}$. Já no ano 1912, o bispo notou que o cônego Carlos carecia de ajuda espiritual. Consciente da real situação do cônego Vincart, o cônego Clemente Laurens pediu ao bispo que não fosse imposta ao cônego Carlos qualquer pena infamante:

isso, em favor do bom nome da nossa Ordem Premonstratense e para o bem espiritual do mesmo religioso. Pensar em fazê-lo voltar para a Abbadia, seria uma catástrofe; isso salta aos olhos de quem avalia a influencia decisiva dos exemplos sobre a formação dos jovens religiosos ${ }^{29}$.

No dia 19 de julho de 1917, cônego Carlos Vincart deixou a cidade de Montes Claros e foi para Jaú, São Paulo, pois a guerra impediu o retorno dele à Bélgica. $\mathrm{O}$ abade quis encontrar os meios para que o cônego fosse para uma abadia da França, mas este preferiu ficar em Jaú. Foi nomeado

${ }^{28}$ Quando o secretário de cônego Carlos retornou a Montes Claros os advogados disseram que ele tinha usado de legítima defesa ou agido debaixo de um acesso de loucura. O cônego Laurens observou que era preciso lembrar que «no sertão de Minas há uma excessiva condescendência para com certos criminosos que gozam de alguma proteção e fortuna» (Carta de Cônego Clemente Laurens ao Bispo Dom João Antônio Pimenta aos 21 de maio de 1916, in ASV, Nunziatura Apostolica in Brasil [19121916], fasc. 771, 144v). Quando o Cônego Carlos Vincart esteve na Bélgica em 1908, ele fez um compra significativa de armas (Cf. Nota Fiscal de Manufacture d'Armes Émile Masquelier, no valor de 436,25 francos, aos 2 de outubro de 1908, in $A A P$ ).

29 Carta de Cônego Clemente Laurens ao Bispo Dom João Antônio Pimenta aos 21 de maio de 1916, in ASV, Nunziatura Apostolica in Brasil (1912-1916), fasc. 771, 145v. 
professor do Colégio dos cônegos premonstratenses de Averbode, permanecendo aí até a sua morte, no dia 9 de dezembro de $1933^{30}$.

Após a saída do cônego Vincart, foi empossado como pároco da paróquia de Montes Claros o padre Manoel Francisco Calado ${ }^{31}$. Na sua posse, aos 22 de julho de 1917, as associações Filhas de Maria, Apostolado da Oração e Conferência São Vicente de Paulo. Ali ele recebeu a seguinte saudação:

Sentimo-nos, entretanto, com necessidade de dizer ao menos isto: o nosso ilustre vigário padre Manoel Francisco Callado, revelou-se, além de fiel compreendedor de seus deveres e zeloso apóstolo da fé e da religião, ser um espírito culto, homem de letras, um orador seguro e eloquente ${ }^{32}$.

E assim, uma vez que cônego Vincart deixou a paróquia depois de 14 anos de apostolado, já afirmavam que padre Manoel era uma excelente aquisição para a sociedade montes-clarense, tanto pelo lado religioso, como pelo lado social. A maneira como os memorialistas de Montes Claros se referem ao «padre Carlos» demonstra que os acontecimentos que causaram a saída desse premonstratense lhes eram totalmente ignorados. As qualidades desse missionário foram prejudicadas pelo seu caráter difícil e irritante. Um de seus pecados foi o seu envolvimento na política local, deixando de lado a sua vida de oração, caindo no descrédito do bispo de Montes Claros.

${ }^{30}$ Cônego Carlos Vincart deixou a seguinte herança em dinheiro: Bank of London = 14:312\$300; Banca Francesa e Italiana 32:539\$100 e Banco do Brasil 51\$300, sendo um total de 46:902\$700 (Cf. Documentos de Montes Claros, in AAP).

${ }^{31}$ Natural de Boliqueime, município de Lolá, na Província de Algarve, sul de Portugal. Nasceu aos 6 de dezembro de 1881. Filho de Francisco José Martins e Maria do Carmo Calado. Ele foi ordenado presbítero em 1905 e foi para o Brasil em 1912. Desde 1913 na diocese de Montes Claros ele ocupou as paróquias de Grão Mogol, Itacambira e Terra Branca até 1917. Na paróquia de Montes Claros ele ficou até 1919 e depois foi para Brejo do Amparo (1920-1926). Em 1926 ele assumiu a paróquia de Brasília de Minas (1926-1940). Ali se mostrou austero exigente em tudo que dizia respeito ao comportamento dos fiéis. Ali ele restaurou as associações do Apostolado da Oração, Pia Filhas de Maria e Conferência São Vicente de Paulo. Afervorou a vida sacramental. Dedicou esforço especial à catequese das crianças. De Brasília de Minas foi para Belo Horizonte em 1940. Ali permaneceu até a sua morte em 1975, com 95 anos de idade (Cf. H. de O. BRAsil, De Contendas à Brasília de Minas, Belo Horizonte 1978, 369-374).

32 «Parochia de Montes Claros, a posse de seu novo parocho», in Montes Claros 62 (26 julho 1917) 1. 


\section{Conclusão}

Os premonstratenses da Abadia do Parc (Bélgica) tinham encontrado em Montes Claros uma situação favorável ao seu objetivo missionário. Já nos primeiros anos de apostolado, ultrapassaram as fronteiras da paróquia de Montes Claros para assistir a outras paróquias que ficavam vacantes. Tudo era promissor. Logo fundaram o Colégio São Norberto para os meninos e solicitaram a vinda das Irmãs do Sagrado Coração de Maria de Berlaar, Bélgica, para a fundação de uma escola para as meninas, como era o costume nessa época. A religião católica de boa parte do extremo Norte de Minas estava nas mãos dos religiosos belgas. Um problema, porém, afetava a vida desses premonstratenses: não conseguiam viver em comunidade.

Durante seu episcopado, D. João lamentou constantemente a situação precária da diocese cuja falta de recursos financeiros lhe impedia que estruturasse bem a diocese nascente. De início viu que da ordem premonstratense não lhe viria nenhum auxílio econômico. O pároco da cidade, cônego Carlos Vincart, não administrava bem o dinheiro e estava envolvido na politicagem local. D. João teve que ter paciência para construir a Igreja Catedral e o prédio do seminário. Todavia, não foram somente os parcos recursos financeiros que dificultavam a missão de D. João na administração do novo bispado. Seu maior sofrimento consistiu no esforço que realizou para melhorar a organização da missão dos premonstratenses belgas. Muitas vezes, procurou despertar, motivar a vida comum dos cônegos regulares premonstratenses para favorecer aquela união interna, alma e coração, expressa em formas externas, mas não viu nenhum resultado. Os religiosos belgas distantes da «solidão» da abadia medieval do Parc, gozavam já de uma vida secularizada no Norte de Minas, quase independentes das exigências da vida canonical. Ao pároco da cidade de Montes Claros, cônego Vincart, era atribuído toda a responsabilidade da desorganização dessa missão devido ao seu caráter «difícil e irritante».

Para melhorar a missão premonstratense na sua diocese, o primeiro bispo de Montes Claros, também de caráter autoritário e impaciente, preferiu resolver o problema pelos caminhos da diplomacia. Procurou, através de uma comunicação constante com os Núncios D. Giuseppe Aversa (1911-1915) e D. Angelo Giacinto Scapardini (1916-1919), esclarecer-lhes a situação dos religiosos belgas em Montes Claros e a necessidade urgente de organização da missão premonstratense. Desde sua chegada ao Brasil, o cônego Vincart procurou manter uma constante comunicação com os representantes da Santa Sé no Brasil e, nessa época, o Núncio D. Giuseppe Aversa era amigo de seu tio que se encontrava como embaixador na Vene- 
zuela. A clareza de D. João, as provas de tudo o que afirmava e a sua importância como bispo da Igreja lhe permitiram melhorar a situação inicial de sua diocese. Conseguiu a saída do cônego Vincart da diocese de Montes Claros.

Todos esses fatos são ignorados pela historiografia norte-mineira porque era próprio do bispo evitar o confronto com a opinião popular. Já era necessário, naquele tempo, especial cautela da autoridade religiosa para resolver qualquer problema que envolvesse o clero e os religiosos. Muitas vezes um padre não agia bem, mas conquistava a simpatia de uma parcela do povo através de algumas concessões para que ficasse de seu lado nas horas mais necessárias. O bispo procurava fugir da possibilidade de um enfrentamento nessas ocasiões. Isso talvez, tenha sido o motivo do desconhecimento dos católicos da região a respeito de muitas decisões que o primeiro bispo de Montes Claros teve que tomar a fim de organizar internamente a Igreja no seu território diocesano.

\begin{abstract}
This paper addresses the Canon Charles Vincart's missionary performance in the first years of Montes Claros' diocese. It intends to analyze his actions in Montes Claros city, his relationship with the other members of the Premonstratensian Order that also lived in Northern Minas Gerais and, especially, with the bishop D. João Antônio Pimenta, as well. Besides, we'll introduce the obstacles suffered by the Norbertine Canon, Charles Vincart, in his missionary performance in the countryside of the Northern Minas Gerais (1903 - 1917). As a parish priest, he was accused by disarranging the Norbertine's mission in the Minas Gerais' countryside due to his "hard and annoying profile".
\end{abstract}

Franscino Oliveira Silva

Professor do Seminário Maior Imaculado Coração de Maria - Montes Claros-MG

Membro do Núcleo de História Regional da Universidade Estadual de Montes Claros-MG 


\section{Bibliografia}

«Clemente Leopoldo Laurens - Necrologia», in Revista Eclesiástica Brasileira, 27 [1967] 509.

Arquivo Secreto Vaticano, Nunziatura Apostolica in Brasil (1912-1916), fasc. 771 (Premostratensi)

Arquivo Secreto Vaticano, S. Congregazione Concistoriale, Visitas Ad Limina, 528 Montisclaren: atos das Visitas ad Limina de 1914 e 1920 [folhas não numeradas].

AZZI, R. A Sé Primacial de Salvador: A Igreja Católica na Bahia [15512001], 2 Vols., Petrópolis 2001.

BENIMELLI, J.A.F. - al., Maçonaria e Igreja Católica: ontem, hoje e amanhã, São Paulo 1983.

BRASIL, H. de O. De Contendas à Brasília de Minas, Belo Horizonte 1978.

CHIAPPETTA, L. Il Codice di Diritto Canonico - commento giuridico pastorale, III, Roma 1986.

DE MARCHI, G: Le Nunziature Apostoliche dal 1800 al 1956, Roma 1957.

HOORNAERT, E. «O Centenário da Posse de Dom Vital», in Revista Eclesiástica Brasileira, 32 [1972] 366.

MILAGROS CÁRCEL ORTÍ, M. - CÁRCEL ORTÍ, V. Historia, Derecho y Diplomática de la visita ad limina, València 1990.

MORANDINI, F. «Mercier, Désiré», in Enciclopedia Cattolica, VIII, Firenze 1950, 713-716.

VIANNA, N. Efemérides Montesclarenses 1707-1962, Rio de Janeiro 1964. 